\title{
Desempenho de novilhos Purunã x Canchim terminados com diferentes níveis de concentrado ${ }^{1}$
}

\author{
Performance of finishing Canchim x Purunã steers fed \\ with different concentrate levels
}

Leandro Bren ${ }^{[a]}$,José Luis Moletta ${ }^{[b]}$, Paulo Rossi Junior ${ }^{[c]}$, Miguel Henrique de Almeida Santana ${ }^{[d]}$

[a] Engenheiro agrônomo, mestre em Ciências Veterinárias, Universidade Federal do Paraná (UFPR), Curitiba, PR - Brasil, e-mail: leandrobren@bol.com.br

[b] Zootecnista, doutor em Zootecnia, pesquisador do Instituto Agronômico do Paraná (IAPAR), Ponta Grossa, PR - Brasil, e-mail:moletta@pr.gov.br

[c] Zootecnista, doutor em Zootecnia, professor associado do Departamento de Zootecnia da Universidade Federal do Paraná (UFPR), Curitiba, PR - Brasil, e-mail: parossi@ufpr.br

[d] Zootecnista, doutor em Zootecnia, Universidade de São Paulo (USP), Pirassununga, SP - Brasil, e-mail: miguel-has@hotmail.com

\section{Resumo}

Avaliou-se o desempenho de novilhos terminados em confinamento por 168 dias, alimentados com níveis crescentes de concentrado na dieta $(0,8 ; 1,1$ e 1,4\% do PV). Foram utilizados 18 animais meio sangue Purunã x Canchim, com média de idade inicial de 12 meses e média de peso inicial de $278 \pm 18 \mathrm{~kg}$. Foi feita a avaliação do consumo de matéria seca total de silagem e concentrado, consumo de proteína, o ganho de peso médio diário e a conversão alimentar. 0 delineamento utilizado foi o inteiramente casualizado com as médias testadas pelo teste de Tukey a $5 \%$ de probabilidade. 0 consumo de matéria seca total aumentou linearmente $(\mathrm{P}<0,01)$ com o aumento de concentrado na dieta, influenciados pelos níveis crescentes de concentrado. A conversão alimentar e o peso final não foram influenciados $(\mathrm{P}>0,05)$ pelo nível de concentrado na dieta. Houve efeito dos tratamentos sobre o ganho de peso médio diário, ganho de peso total e consumo de proteína $(\mathrm{P}<0,01)$. A suplementação com concentrado pode aumentar o desempenho em crescimento, porém, não melhora a eficiência alimentar.

Palavras-chave: Bovinos de corte. Conversão alimentar. Eficiência nutricional. Ganho de peso. Ingestão de concentrado.

\footnotetext{
1 Parte da Dissertação de Mestrado em Ciências Veterinárias - Produção Animal, apresentada pelo primeiro autor à CPGCV/UFPR.
} 


\section{Abstract}

It was analyzed the effect of adding increasing levels of concentrate $(0.8,1.1$ and $1.4 \%$ of body weight) in the diet of finishing steers for 168 days. Eighteen Purunã x Canchim crossbred steers (12 months of age) were evaluated with initial body weight averaging $278 \pm 18 \mathrm{~kg}$. Total dry matter, silage, concentrate and protein intake were analyzed, as well as the average daily gain and feed conversion ratio. For this experiment, it was established a completely randomized design and the means were compared using Tukey's test at 5\% probability. Total dry matter intake increased linearly $(P<0.05)$ with the increasing levels of concentrate, while feed conversion rate and final body weight were not affected $(P>0.05)$ by them. Treatments also caused a significant effect on daily average gain, total weight gain and protein intake $(P<0.01)$. In conclusion, concentrate supplementation improves growth performance, however, it does not improve feed efficiency.

Keywords: Average daily gain. Beef cattle. Feed conversion ratio. Nutritional efficiency. Concentrate intake.

\section{Introdução}

0 termo mais comumente utilizado para descrever o limite máximo de apetite é o consumo voluntário, obtido quando o alimento é oferecido ad libitum. $\mathrm{O}$ consumo é um dos pontos importantes que podem limitar o nível de produtividade em bovinos de corte, ou seja, maiores ganhos de peso em intervalos mais curtos (CARVALHO et al., 1997).

0 consumo de dietas com altos teores de fibra é controlado por fatores físicos como a taxa de passagem e enchimento ruminal, ao passo que dietas com altos teores de concentrado (alta densidade energética) têm consumo controlado pela demanda energética e por fatores metabólicos que refletem a homeostase (NRC, 2000). Normalmente, o animal consome o alimento para manter a ingestão de energia constante e, uma vez que a ingestão de matéria seca diminui com o aumento da digestibilidade do alimento, o fator que irá determinar a saciedade controlando a ingestão, nesse caso, é a densidade calórica da ração (VAN SOEST, 1994).

O consumo de matéria seca pode ser influenciado por fatores fisiológicos como tamanho e composição corporal (especialmente a gordura), demanda da produção, sexo, idade, estágio fisiológico, efeitos ambientais (temperatura, clima e fotoperíodo), manejo alimentar e disponibilidade da forragem, além de efeitos das dietas como conteúdo de água do alimento, grau de fermentação em silagens, teor de proteína e formas de processamento (BÜRGER et al., 2000).
Diversos trabalhos demonstram que existem diferenças no consumo se há alterações na proporção entre volumoso e concentrado, ou seja, o consumo tende a aumentar até certos limites conforme se aumenta a proporção de concentrado na dieta (RODRIGUEZ et al., 1996; MOREIRA et al., 2003; TIBO et al., 2000).

O desempenho econômico da engorda de bovinos em confinamento não depende só do potencial genético, mas também da qualidade e manejo da alimentação. Pode-se maximizar a produção aumentando-se o ganho diário de peso, utilizando-se concentrados em dietas balanceadas para animais em confinamento (OLIVEIRA et al., 1998). No entanto, a melhoria do nível nutricional com maiores quantidades de concentrado pode inviabilizar a atividade em razão do alto custo (RESTLE, 1997). Dessa forma, o ganho de peso e a conversão alimentar são importantes medidas na avaliação dos animais para melhor compreender sua eficiência, ao utilizar o alimento fornecido, para a produção de carne. Avaliou-se, assim, o consumo de matéria seca, consumo de proteína, ganho de peso e a conversão alimentar de novilhos confinados recebendo dietas com níveis crescentes de concentrado.

\section{Material e métodos}

O experimento foi realizado no período de junho a novembro de 2001, na cidade de Ponta Grossa (PR) no Instituto Agronômico do Paraná. A fase de confinamento teve duração de 168 dias, dividida em seis 
períodos de 28 dias, sendo os animais abatidos com idade média de 17 meses. Foram utilizados 18 animais machos não castrados, 1/2 sangue Purunã/Canchim, com idade média inicial de 12 meses e peso inicial médio de $278 \mathrm{~kg} \pm 18 \mathrm{~kg}$, confinados em baias individuais medindo $8 \mathrm{~m}^{2}$, totalmente cobertas, providas de bebedouro e cochos individuais para volumoso, concentrado e suplemento mineral (80 gramas de fósforo/ kg).

Os tratamentos foram divididos de acordo com os níveis de concentrado na dieta e fornecidos com base no peso vivo (PV) dos animais, ajustados a cada 28 dias. Os tratamentos experimentais foram: $\mathrm{T} 1=0,8 \%$ do $\mathrm{PV}, \mathrm{T} 2=1,1 \%$ do $\mathrm{PV}$ e T3 $=1,4 \%$ do PV com 6 animais por tratamento.

Os animais foram alimentados com silagem de milho ad libitum e concentrado $25 \%$ de farelo de soja, $73 \%$ de grãos de milho moído e $2 \%$ de suplemento mineral). As dietas foram balanceadas para serem isonitrogenadas e a quantidade de proteína bruta (PB) ajustada por meio do incremento de uréia nas rações. A composição bromatológica do concentrado e volumoso utilizada foi estimada pela metodologia de Weende e Van Soest (AOAC, 1995) e pode ser observada na Tabela 1.

Tabela 1 - Composição bromatológica da dieta experimental

\begin{tabular}{lcc}
\hline Item & $\begin{array}{c}\text { Concentrado } \\
\text { experimental }\end{array}$ & $\begin{array}{c}\text { Silagem } \\
\text { de milho }\end{array}$ \\
\hline Matéria seca (\%) & 88,39 & 26,6 \\
Proteína bruta (\% MS) & 18,09 & 6,4 \\
Extrato etéreo (\% MS) & 4,10 & - \\
Matéria mineral (\%) & 4,45 & - \\
Fibra em detergente neutro (\%) & - & 54,9 \\
Fibra em detergente ácido (\%) & - & 32,7 \\
Cálcio (\%) & 0,37 & 0,28 \\
Fósforo (\%) & 0,51 & 0,25 \\
Magnésio (\%) & - & 0,19 \\
Potássio (\%) & - & 0,92 \\
\hline
\end{tabular}

Nota: Dados representados por hífen não foram avaliados na análise bromatólógica.

Fonte: Dados da pesquisa.

Antecedendo à fase de avaliação, os animais foram confinados em baias coletivas por um período de 65 dias para adaptação ao manejo e à dieta alimentar, sendo submetidos a uma dieta comum, composta de silagem de milho ilimitada e concentrado fornecidos na proporção de $1 \%$ do PV.
Na fase efetiva de confinamento (168 dias), os novilhos foram pesados no início do experimento e a cada 28 dias. Anteriormente às pesagens, foram submetidos a um jejum alimentar de 16 horas. Ao final de cada um dos períodos, a quantidade de alimento concentrado foi ajustada. A dieta proposta foi fornecida duas vezes ao dia, às 8 e às 14 horas. Nas pesagens foram obtidos os dados de ganho de peso médio diário (GMD) de cada animal.

As sobras foram retiradas e pesadas diariamente, antes do fornecimento de concentrado e volumoso, das quais as sobras eram analisadas para a obtenção do consumo de matéria seca dos animais. 0 mesmo foi fornecido ad libitum, sendo ajustado de acordo com o consumo do dia anterior, procurando-se deixar uma sobra no cocho entre 5 a $10 \%$. 0 suplemento mineral foi fornecido à vontade, de acordo com as exigências para animais em crescimento dessa idade (NRC, 2000).

No início da fase experimental, os animais foram submetidos à adaptação de quatro dias, recebendo $30 \mathrm{~g}$ de ureia. Após o período, as dietas foram formuladas para os tratamentos em estudo, visando propiciar GMD de 1,200 kg/dia. Seu desempenho durante o confinamento foi avaliado por meio do consumo de matéria seca (kg de MS/dia), conversão alimentar (kg de MS ingerida/kg de GMD), consumo de proteína ( $\mathrm{kg} / \mathrm{dia})$, GMD (kg/dia), peso inicial $(\mathrm{kg})$ e peso final $(\mathrm{kg})$.

0 delineamento experimental adotado foi inteiramente casualizado, composto por três tratamentos (T1, T2 e T3) e considerando cada animal uma repetição, totalizando seis repetições por tratamento.

Os dados foram analisados utilizando-se o software Statistical Analisys System versão 9.1 (SAS, 2002). Para a comparação das médias foi utilizado o teste Tukey a $5 \%$ de probabilidade e para o consumo de matéria seca ( $\mathrm{kg} /$ dia) foi utilizada análise de regressão entre a porcentagem de concentrado fornecida e o consumo de matéria seca em $\mathrm{kg}$ por cabeça por dia.

\section{Resultados}

Houve efeito de tratamento $(\mathrm{P}<0,05)$ sobre o consumo de matéria seca $(\mathrm{kg} / \mathrm{dia})$. Maior consumo de matéria seca (Tabela 2) foi observado para 
os animais que receberam $1,4 \%$ do PV em concentrado $(\mathrm{P}<0,05)$. No entanto, não ocorreu diferença estatística $(\mathrm{P}>0,05)$ entre os tratamentos $0,8 \mathrm{e}$ $1,1 \%$ do peso vivo, que apresentaram os menores consumos.

Tabela 2 - Consumo diário de matéria seca das rações experimentais de bovinos Purunã/Canchim, segundo os níveis de concentrado na dieta

\begin{tabular}{|c|c|c|c|c|}
\hline \multirow[b]{2}{*}{ Variáveis } & \multicolumn{3}{|c|}{ Tratamentos } & \multirow[b]{2}{*}{ CV (\%) } \\
\hline & $\begin{array}{c}0,8 \% \\
\text { PV }\end{array}$ & $\begin{array}{c}1,1 \% \\
\text { PV }\end{array}$ & $\begin{array}{c}1,4 \% \\
\text { PV }\end{array}$ & \\
\hline Consumo de Matéria Seca & $7,49^{b}$ & $7,70^{\mathrm{b}}$ & $8,58^{a}$ & 6,02 \\
\hline $\begin{array}{l}\text { Consumo de silagem } \\
\text { (kg/animal) }\end{array}$ & $17,16^{\mathrm{a}}$ & $15,01^{\mathrm{ab}}$ & $13,31^{b}$ & 12,27 \\
\hline $\begin{array}{l}\text { Consumo de concentrado } \\
\text { (kg/animal) }\end{array}$ & $2,73^{b}$ & $3,96^{a}$ & $4,43^{a}$ & 14,45 \\
\hline
\end{tabular}

Nota: Médias com letras diferentes na mesma linha diferem entre si pelo teste de Tukey $(P<0,05)$.

Legenda: PV - Peso vivo.

Fonte: Dados da pesquisa.

O consumo de proteína bruta durante os períodos experimentais está apresentado na Tabela 3. Para os cálculos foram utilizados os valores de $30 \%$ de matéria seca e 7,5\% de proteína bruta para a silagem de milho e de $80 \%$ de matéria seca e $17,5 \%$ de proteína bruta para o concentrado. Embora se tenha ajustado o nível de proteína nas dietas para que fossem isonitrogenadas, houve diferenças no consumo de proteína bruta entre os tratamentos nos diferentes períodos experimentais (Tabela 3 ).

Com exceção do primeiro período, o maior consumo de proteína bruta ocorreu no tratamento de maior nível de concentrado (T3), seguido do tratamento de nível intermediário (T2) e o menor nível (T1) apresentando o menor consumo $(\mathrm{P}<0,05)$.

As médias do PV inicial, $\mathrm{PV}$ final, ganho de peso total, GMD e conversão alimentar (CA) correspondentes ao período total de confinamento para os três tratamentos estão apresentadas na Tabela 4.

Os níveis de concentrado na dieta tiveram efeito sobre o ganho de peso total $(\mathrm{P}<0,05)$. Os animais do T3 apresentaram maior ganho de peso total em relação aos que receberam $0,8 \%$ e 1,1\%.

Os níveis de concentrado também influenciaram no GMD, que foi observado nos animais alimentados com o maior nível de concentrado na dieta,
Tabela 3 - Consumo de proteína bruta ( $\mathrm{kg} / \mathrm{animal} / \mathrm{dia}$ ) nos períodos e média do período total, em função dos níveis de concentrado na dieta

\begin{tabular}{lcccc}
\hline \multirow{2}{*}{ Período } & \multicolumn{3}{c}{ Tratamentos } & \\
\cline { 2 - 4 } & $\mathbf{0 , 8 \%}$ & $\mathbf{1 , 1 \%}$ & $\mathbf{1 , 4 \%}$ & $\mathbf{C V}(\%)$ \\
\hline 1 & $\mathbf{P V}$ & $\mathbf{P V}$ & $\mathbf{P V}$ & \\
\hline 2 & 0,892 & 0,887 & 0,928 & 4,44 \\
3 & $0,751^{\mathrm{c}}$ & $0,839^{\mathrm{b}}$ & $0,974^{\mathrm{a}}$ & 4,91 \\
4 & $0,840^{\mathrm{c}}$ & $0,931^{\mathrm{b}}$ & $1,065^{\mathrm{a}}$ & 5,18 \\
5 & $0,886^{\mathrm{c}}$ & $1,004^{\mathrm{b}}$ & $1,144^{\mathrm{a}}$ & 5,45 \\
6 & $0,947^{\mathrm{c}}$ & $1,053^{\mathrm{b}}$ & $1,220^{\mathrm{a}}$ & 5,17 \\
Média do período total & $0,971^{\mathrm{c}}$ & $1,084^{\mathrm{b}}$ & $1,263^{\mathrm{a}}$ & 5,25 \\
\hline
\end{tabular}

Nota: Médias com letras diferentes na mesma linha diferem entre si pelo teste de Tukey $(P<0,05)$.

Legenda: PV - Peso vivo.

Fonte: Dados da pesquisa.

Tabela 4 - Peso vivo inicial e final, ganho de peso total, ganho de peso diário e conversão alimentar de novilhos Purunã x Canchim, segundo os percentuais de concentrado na dieta

\begin{tabular}{lcccc}
\hline \multirow{2}{*}{ Variáveis } & \multicolumn{3}{c}{ Tratamentos } & \\
\cline { 2 - 4 } & $\mathbf{0 , 8 \%}$ & $\mathbf{1 , 1 \%}$ & $\mathbf{1 , 4 \%}$ & CV (\%) \\
& $\mathbf{P V}$ & $\mathbf{P V}$ & $\mathbf{P V}$ & \\
\hline Peso vivo inicial $(\mathrm{kg})$ & 278,50 & 277,83 & 279,50 & 7,41 \\
Peso vivo final $(\mathrm{kg})$ & 426,33 & 456,20 & 480,25 & 7,95 \\
Ganho de peso total $(\mathrm{kg})$ & $161,00^{\mathrm{b}}$ & $178,50^{\mathrm{ab}}$ & $201,33^{\mathrm{a}}$ & 10,33 \\
Ganho de peso médio & $1,049 \mathrm{c}$ & $1,177^{\mathrm{b}}$ & $1,310^{\mathrm{a}}$ & 8,99 \\
diário $(\mathrm{kg})$ & 6,72 & 5,90 & 7,21 & 31,86 \\
\hline Conversão alimentar & & &
\end{tabular}

Nota: Médias com letras diferentes na mesma linha diferem entre si pelo teste de Tukey $(P<0,05)$.

Legenda: PV - Peso vivo.

Fonte: Dados da pesquisa.

decrescendo para os níveis inferiores. 0 menor nível de concentrado propiciou o menor GMD. No entanto, não foi observada diferença $(\mathrm{P}>0,05)$ para o ganho de peso total entre os tratamentos que receberam 1,1 e $1,4 \%$ do peso vivo.

\section{Discussão}

Segundo Resende et al. (2001), o esvaziamento do trato gastrintestinal é dado pelo aumento na taxa 
de passagem; assim, a ingestão é inversamente relacionada ao conteúdo de FDN (fibra em detergente neutro) da dieta. Quando a quantidade da dieta é limitante, os animais não são capazes de consumir quantidades suficientes de matéria seca para atender às suas necessidades energéticas, o que implica em queda no desempenho. Por outro lado, a ingestão e a digestibilidade são negativamente correlacionadas quando se utilizam dietas de alta qualidade, em que a fração fibrosa (fibra em detergente neutro) é pequena e, provavelmente, não influi na ingestão, que será controlada pelo requerimento energético do animal.

O menor consumo verificado para os animais dos tratamentos T1 e T2, quando comparados com os novilhos do T3, pode ter ocorrido porque os animais do T1 e T2 consumiram mais silagem e menos concentrado (Tabela 2), possivelmente promovendo-lhes um maior enchimento ruminal devido aos aumentos nos níveis de fibra que reduzem a taxa de passagem (TIBO et al., 2000).

Ítavo et al. (2002) trabalharam com novilhos Nelore alimentados com dietas contendo 20, 40, 60 e $80 \%$ de concentrado e dois níveis de proteína bruta, 15 e $18 \%$. 0 volumoso utilizado foi o feno de capim Tifton 85, e observou-se redução linear do consumo de matéria seca ao aumento dos níveis de concentrado. Já Rodriguez et al. (1996) e Oliveira et al. (1998) observaram comportamento quadrático do nível de concentrado na ração sobre o consumo de matéria seca, assim como Putrino et al. (2007), que encontraram o mesmo comportamento no consumo de matéria seca com o aumento dos níveis de concentrado de $20 \%$ para $60 \%$.

O consumo de proteína bruta por dia do presente estudo, comparado ao trabalho de Veloso et al. (2002), seria insuficiente para proporcionar ganhos de peso na ordem de $1 \mathrm{~kg} /$ dia em novilhos F1 Limousin x Nelore para o T1. Já nos demais níveis, o consumo de PB apresentou-se dentro dos valores para esse patamar de ganho.

Carvalho et al. (1997) avaliaram a utilização de diferentes níveis de concentrado sobre o consumo e a digestibilidade em zebuínos, e não verificaram alteração no consumo de proteína bruta, com valores médios de consumo variando entre 0,422 a 0,498 g/dia. De acordo com esses autores, a ausência de efeito dos níveis de concentrado sobre o consumo de proteína bruta pode ser explicada pelo fato das rações serem isonitrogenadas e dos consumos de matéria seca não terem sido alterados. Os níveis de energia, porém, promoveram alterações no consumo de matéria seca, o que explica a variação encontrada para o consumo de proteína bruta no presente estudo.

Diferenças no GMD entre os tratamentos podem ter ocorrido pelo aumento de nutrientes digestíveis totais na dieta devido ao acréscimo de concentrado, mas podem também ter ocorrido pela variação do consumo de PB.

Montanholi et al. (2002) obtiveram ganhos de peso diário de $1,37 \mathrm{~kg} /$ dia em animais da raça Pardo Suíço com idade média de oito meses, recebendo 1,3\% do peso vivo em concentrado. Todavia, os resultados para ganho de peso diário obtidos no presente trabalho são superiores aos encontrados por Silva et al. (1999), que verificaram ganhos de peso de 1,16; 1,19 e 1,25 kg/dia para animais alimentados com 25 , 35 e $45 \%$ de concentrado na dieta, respectivamente.

Aumentos nos ganhos de peso diário com a elevação no nível de concentrado na dieta foram obtidos por Restle et al. (1999a) que, ao submeterem novilhos inteiros a diferentes níveis de concentrado na dieta $(0,6 ; 0,9$; e $1,2 \%$ do peso vivo), observaram uma redução nos dias de terminação, devido ao aumento do ganho de peso médio diário.

Os maiores ganhos médios diários para os tratamentos T2 e T3 mostraram o efeito positivo do aumento de concentrado na dieta, uma vez que animais alimentados com maiores níveis do alimento podem atingir o peso pré-determinado de abate em um menor espaço de tempo, encurtando os dias de confinamento.

Mesmo havendo diferenças no consumo de matéria seca de silagem e concentrado, não houve efeito $(\mathrm{P}>0,05)$ do nível de concentrado na dieta sobre a conversão alimentar (Tabela 4). Resultados similares foram encontrados por Silva et al. (2000), que ao avaliarem o desempenho de novilhos Nelore alimentados com silagem de sorgo e 20, 40, 60 e $80 \%$ de concentrado na base da matéria seca, não verificaram efeito do nível de concentrado sobre a conversão alimentar. Da mesma forma, Restle et al. (1999b) e Montagner et al. (2000) não verificaram melhora na conversão alimentar quando utilizaram diferentes níveis de concentrado na dieta. A não melhoria da conversão alimentar apresentada 
por esses autores, assim como no presente estudo, pode ser explicada pelo fato de que os aumentos no ganho de peso não são compensados pelos maiores aumentos no consumo de matéria seca. Portanto, a conversão alimentar não é afetada.

Melhores conversões alimentares com o aumento de concentrado na dieta foram verificadas por Silva et al. (1999). Os autores encontraram uma melhora linear da conversão em animais na fase de terminação alimentados com silagem de sorgo forrageiro de alta produção de grãos (AG 2002) associada a níveis crescentes de concentrado na dieta (25, 35 e 45\%). De modo semelhante, Oliveira et al. (1998), Ferreira et al. (1998) e Ítavo et al. (2002) verificaram efeito linear dos níveis de concentrado sobre a conversão alimentar, ocorrendo melhora da conversão com o aumento do teor de concentrado nas rações.

\section{Conclusões}

0 aumento no ganho de peso devido ao aumento na ingestão de concentrado pode não melhorar a conversão alimentar dos animais, principalmente devido ao maior consumo de matéria seca.

São recomendados níveis de concentrado de $1,4 \%$ de peso vivo na dieta para um aumento no ganho de peso sem alteração da conversão alimentar.

\section{Referências}

ASSOCIATION OF OFFICIAL AGRICULTURAL CHEMISTS AOAC. Official methods of analysis. 16. ed. Washington, DC: AOAC, 1995.

BÜRGER, P. J. et al. Consumo e digestibilidade aparente total e parcial em bezerros holandeses alimentados com dietas contendo diferentes níveis de concentrado.

Revista Brasileira de Zootecnia, v. 29, n. 1, p. 206-214, 2000. doi:10.1590/S1516-35982000000100028.

CARVALHO, A. U. et al. Níveis de concentrado em dietas de Zebuínos. 1. consumo e digestibilidade aparente. Revista Brasileira de Zootecnia, v. 26, n. 5, p. 986-995, 1997.

FERREIRA, M. A. et al. Consumo, conversão alimentar, ganho de peso e características de carcaça de bovinos F1 Simental x Nelore. Revista Brasileira de Zootecnia, v. 28, n. 2, p. 343-351, 1998.
ÍTAVO, L. C. V. et al. Níveis de concentrado e proteína bruta na dieta de bovinos Nelore nas fases de recria e terminação: consumo e digestibilidade. Revista Brasileira de Zootecnia, v. 31, n. 2, p. 1033-1041, 2002. doi:10.1590/ S1516-35982002000400028.

MONTAGNER, D. et al. Desempenho de novilhos recebendo diferentes níveis de concentrado com dois níveis de resíduo de soja no concentrado. In: REUNIÃO ANUAL DA SOCIEDADE BRASILEIRA DE ZOOTECNIA, 37., 2000, Viçosa. Anais... Viçosa: Sociedade Brasileira de Zootecnia, 2000. CD-ROM.

MONTANHOLI, Y. R. et al. Avaliação do desempenho de bezerros inteiros Pardo Suíço em três sistemas de alimentação. In: REUNIÃO ANUAL DA SOCIEDADE BRASILEIRA DE ZOOTECNIA, 39., 2002. Recife. Anais... Recife: Sociedade Brasileira de Zootecnia, 2002. CD-ROM.

MOREIRA, J. F. C. et al. Concentrados protéicos para bovinos. 1. Digestibilidade in situ da matéria seca e da proteína bruta. Arquivo Brasileiro de Medicina Veterinária e Zootecnia, v. 55, n. 3, p. 324-333, 2003. doi:10.1590/ S0102-09352003000300011.

NATIONAL RESEARCH COUNCIL - NRC. Nutrient requirements of beef cattle. 7. ed. Washington, DC: National Academy of Sciences, 2000.

OLIVEIRA, S. R. et al. Desempenho de novilhos Nelore, não castrados, recebendo rações com vários níveis de concentrado. In: REUNIÃO ANUAL DA SOCIEDADE BRASILEIRA DE ZOOTECNIA, 35., 1998. Botucatu. Anais... Botucatu: Sociedade Brasileira de Zootecnia, 1998. CD-ROM.

PUTRINO, S. M. et al. Digestibilidade aparente de dietas com níveis crescentes de concentrado em novilhos Brangus e Nelore. Arquivo Brasileiro de Medicina Veterinária e Zootecnia, v. 59, n. 2, p. 406-413, 2007. doi:10.1590/S0102-09352007000200022.

RESENDE, F. D. et al. Bovinos mestiços alimentados com diferentes proporções de volumoso:concentrado. Efeito sobre a ingestão de nutrientes. Revista Brasileira de Zootecnia, v. 30 , n. 1, p. 270-279, 2001. doi:10.1590/ S1516-35982001000100037.

RESTLE, J. Confinamento de terneiros. In: RESTLE, J. et al. (Eds.). Técnicas avançadas na recria e engorda de bovinos de corte. Santa Maria: Universidade Federal de Santa Maria, 1997. p. 51-67. 
RESTLE, J. et al. Níveis de concentrado na terminação de novilhos associados a duas silagens de sorgo ou na suplementação da pastagem de inverno. In: REUNIÃo ANUAL DA SOCIEDADE BRASILEIRA DE ZOOTECNIA, 36., 1999a. Porto Alegre. Anais... Porto Alegre: Sociedade Brasileira de Zootecnia, 1999a. CD-ROM.

RESTLE, J. et al. Produção de terneiros para abate aos 12 meses, alimentados com silagens de milho colhido a duas alturas de corte, associadas a dois níveis de concentrado. In: REUNIÃO ANUAL DA SOCIEDADE BRASILEIRA DE ZOOTECNIA, 36., 1999b. Porto Alegre. Anais... Porto Alegre: Sociedade Brasileira de Zootecnia, 1999b. CD-ROM.

RODRIGUEZ, L. R. R. et al. Consumo de rações contendo quatro níveis de concentrado por bovinos holandeses e nelores e por bubalinos. Revista Brasileira de Zootecnia, v. 25, n. 3, p. 568-581, 1996.

STATISTICAL ANALISYS SYSTEM - SAS. System for Microsoft Windows. Release 9.1. Cary: Statistical Analysis System Institute, 2002.

SILVA, F. F. et al. Desempenho produtivo de novilhos Nelore na recria e terminação com diferentes níveis de concentrado na dieta. In: REUNIÃO ANUAL DA SOCIEDADE BRASILEIRA DE ZOOTECNIA, 37., 2000, Viçosa. Anais... Viçosa: Sociedade Brasileira de Zootecnia, 2000. CD-ROM.
SILVA, N. L. Q.et al. Terminação de novilhos alimentados com silagens de sorgo associadas a três níveis de concentrado na dieta. In: REUNIÃO ANUAL DA SOCIEDADE BRASILEIRA DE ZOOTECNIA, 36., 1999. Porto Alegre. Anais... Porto Alegre: Sociedade Brasileira de Zootecnia, 1999. CD-ROM.

TIBO, G. C. et al. Níveis de concentrado em dietas de novilhos mestiços F1 Simental x Nelore. 1 Consumo e Digestibilidade. Revista Brasileira de Zootecnia, v. 29, n. 3, p. 910-920, 2000. doi:10.1590/ S1516-35982000000300038.

VAN SOEST, P. J. Nutritional ecology of the ruminant. Ithaca: Comstock Publishing Associates, 1994.

VELOSO, C. M. et al. Composição corporal e exigências energéticas e protéicas de bovinos F1 Limousin x Nelore, não-castrados, alimentados com rações contendo diferentes níveis de concentrado. Revista Brasileira de Zootecnia, v. 31, n. 3, p. 1273-1285, 2002. doi:10.1590/ S1516-35982002000500026.
Recebido: $15 / 03 / 2013$

Received: 03/15/2013

Aprovado: 06/03/2014

Approved: 03/06/2014 